\title{
High Value Materials from the Forests
}

\author{
Geoffrey R. Mitchell*, Sara Biscaia, Vidhura Subash Mahendra, Artur Mateus \\ Centre for Rapid and Sustainable Product Development, Polytechnic Institute of Leiria, \\ Marinha Grande, Portugal \\ Email: *geoffrey.mitchell@ipleiria.pt
}

Received 6 November 2015; accepted 14 March 2016; published 17 March 2016

Copyright (C) 2016 by authors and Scientific Research Publishing Inc.

This work is licensed under the Creative Commons Attribution International License (CC BY). http://creativecommons.org/licenses/by/4.0/

(c) (i) Open Access

\section{Abstract}

The design, process and synthesis of high value composite materials from forests in scientific research has been widely discussed in recent times ensuring greater awareness and accessibility to its associated communities and the economy in general. Raw materials obtained from the forests can be multi-folded in its use as a virgin source of an energy provider such as wooden blocks to more complex processed material development. In this paper, we will be focusing on the latter related to sustainable development of rosins. Rosins are exudates of pine resins which consist of hydrophobic characteristics that are widely used as a precursor for many applications without significant alterations. We discuss the nature, process and its support in composite material. The composite material has been tailored with related to chemical and physical properties. Chemically rosins contain free carboxyl acid functional group and carbon-carbon double bonds which are potent to react with other reactive species to facilitate various intermediates. Here we have looked at its reaction intermediates and subsequent products for composite material of high value using environmentally friendly methodologies, such as solvent free methods. Biodegradable polymer incorporated composite scaffolds using rosins are studied to tailor the bioactivity. We treat the eco-friendly pine resins which is biocompatible to complement the biopolymers as the process of extracting rosin from pine resin is a particular green process, involving only a natural product (pine resin) and producing no waste. The paper discusses the preparation of composite scaffolds for use in tissue engineering applications.

\section{Keywords}

Biopolymers, Composites, Tissue Engineering, Scaffolds, Biomanufacturing

\section{Introduction}

The global interest in sustainable product development has increased in recent years due to excessive usage of

\footnotetext{
"Corresponding author.
} 
non-recyclable advanced materials, their applications leading to certain irreversible ecological impacts. In the light of such impact European Union (EU) forest-based industries have taken a significant turn to generate value added end products.

\subsection{EU Forest-Based Industries}

The EU Forest-based Industries (EUF-BI) include the woodworking, the furniture, the pulp \& paper manufacturing and converting and the printing industry [1]. Together, they represent about $7 \%$ of EU manufacturing GDP and nearly 3.5 million jobs. The EU F-BI thus form an important part of the EU's manufacturing industry and their growth can help achieve the goals of the EU's Industrial Policy [2], including the aspirational goal of raising manufacturing industries' contribution to EU GDP from $15.3 \%$ (2012) to 20\%, i.e. the "reindustrialisation" of Europe. However, EU-grown wood is becoming increasingly sought after through growing competition, already from bio-energy and in the future from the emerging bio-based industries. Although wood prices fluctuate, any increases further squeeze thin margins which cannot be compensated elsewhere. For example, the F-BI's other raw materials are often imported and hence prone to price volatility. Their bought-in process energy is more expensive and both their environmental and social standards are higher than those of most global competitors. Demand for "traditional" wood-based products, such as in construction and furniture, remains depressed; consumption of some paper grades and printed paper goods is declining in the face of electronic media and is only partially compensated by increases for other formats such as printing on plastics and textiles.

However, for convenience and brevity, the term "forest-based industries", abbreviated to "F-BI", is retained here as convenient shorthand to cover all these four sub-sectors. Based on these, four distinct but inter-linked FBI value chains have been identified, so as to include the F-BI's emerging bio-economy component: (Figure 1)

- Wood \& wooden products: production of round \& sawn wood, panels, other wooden products, including wood fuels; cork processing;

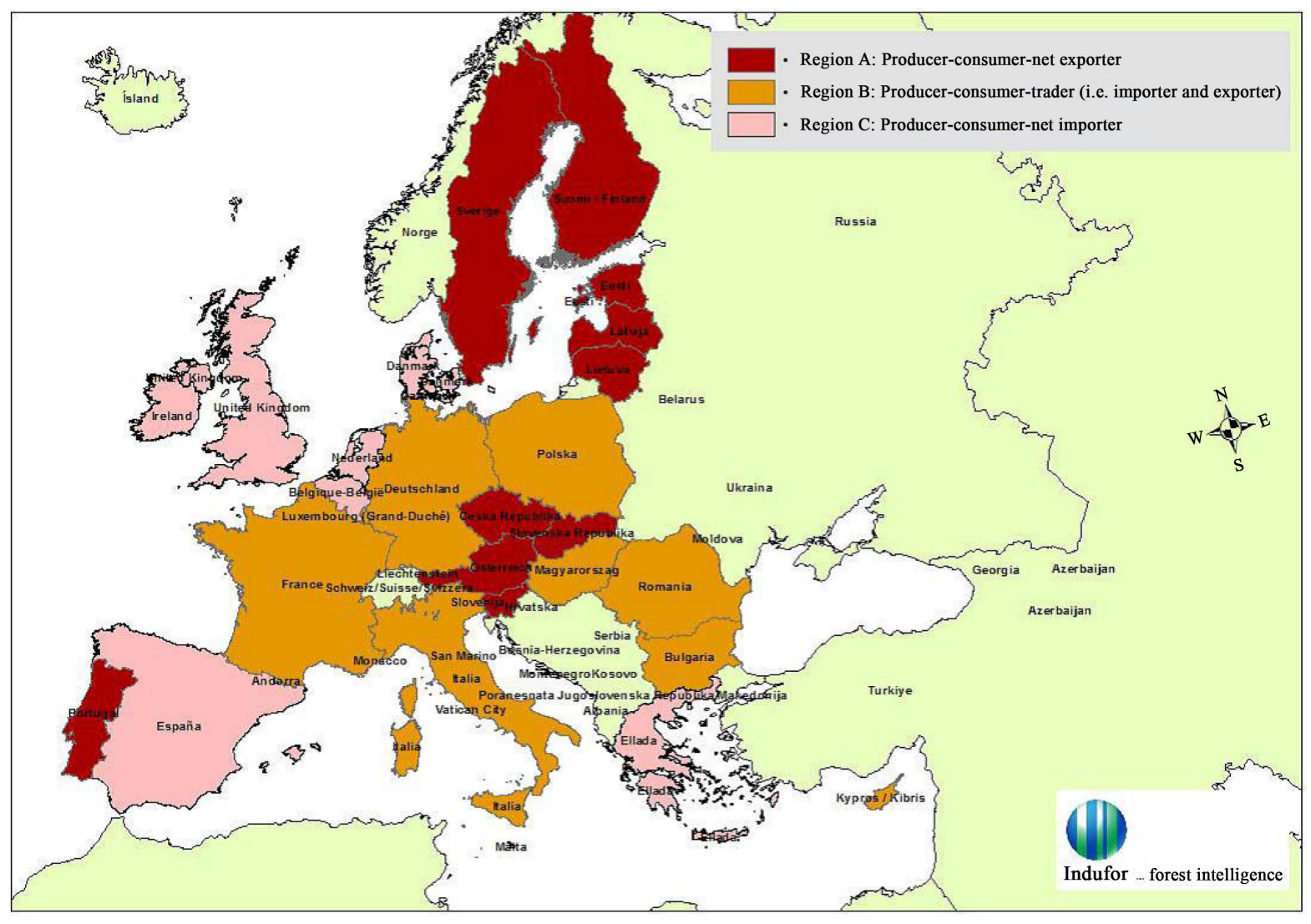

Figure 1. Map of EU-27 Member States as types of region for forest-based industries [3]. 
- Furniture and furnishings of wood and other materials, their components and by products;

- Cellulose fibre pulp, paper \& paperboard manufacturing and converting; printing and paper-media publishing; precursors for textiles;

- Wood bio-refineries, refining ligno-cellulose into: transport bio-fuels; composite materials and chemical feed-stocks and products.

\subsection{Wood Associated Derivatives for Industry}

Molecules such as sugars [4] and wood derivatives (e.g. terpenes, rosin, lignin, cellulose) [5]-[7] are very important feedstock to design novel monomers for the synthesis of polymeric materials with original features and properties. Bio-resources derived from pine trees have aroused interest due to their abundance, low cost and easy chemical modifications [8]. The warm summer temperatures conducive to high resin flow and the large areas of natural pine exists made Portugal and some Mediterranean countries major producers of gum naval stores in the past. However, increasing labour costs and the growing reluctance amid workers to undertake tapping over of the trees for the last 30 or so years has led to a steady decline in resin-based productions in Portugal. While the use of pine resins as a natural resource has decreased an alternate crop in eucalyptus due to its rapid growth and enhanced productivity has somewhat thrived.

\subsection{Pine Resins as a Precursor for High End Productivity}

Rosins are solid form of resins obtained from pines and similar types of plants belonging to the conifer family, produced by heating fresh liquid resin to vaporize the volatile liquid terpene (large group of unsaturated hydrocarbons) components. It is semi-transparent and varies in colour from yellow to black. The pine resin isolated by tapping the tree approximately contains $70 \%$ rosin, $15 \%$ turpentine and $15 \%$ debris and water [9]. At room temperature rosin is brittle, but it softens at oven temperatures.

Even though the production of turpentine (ca. 15\% of the crude resin) has been one of the common extractions as that can be used as an antecedent in organic synthetic chemistry the use of rosins has been underused and failed to be appreciated. In Portugal pine resin is heated in an open fire using a large sealed vessel with a condensing coil where the turpentine would be condensed leaving the liquid rosin in the bottom [10]. The liquid rosin is subsequently transferred to metal trays to cool and harden.

The term "resin" is generally referred to the plant sap or the exudate but this definition is somewhat obscure as it contains gums, mucilage, oils, waxes and latex [11]. Nevertheless, a better definition can be deduced based on its chemistry, secretory structures and functions in the plant. Rosin [12] chiefly consists of different resin acids, especially abietic acid and are not polymers like hydrocarbon resins but a blend of molecules with a mixture of eight closely related rosin acids characterized by three fused six-carbon rings, double bonds that vary in number and location, and a single carboxylic acid group as illustrated (Figure 2). The ratio of these isomers in rosin depends on the collection method and the species of the tree from which the rosin was produced. Abietic acid, with its rigid tricyclic skeleton possessing two double bonds and a carboxylic functional group appears to be an interesting platform towards stiff bio-based polymers [13]. The molecular weight of the rosin is quite different compared to hydrocarbon resins. It is classified into three main types; gum rosin, wood rosin and tall rosin. Gum rosin (Figure 3) shown in a cup of resins collected from the tree is the most common rosin obtained from the pine trees by tapping the living pine tree [14].

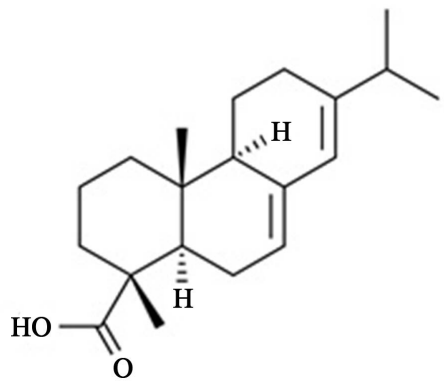

Figure 2. The chemical structure of a rosin acid-abietic acid. 


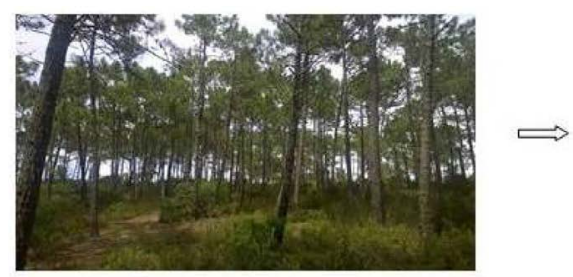

(a)

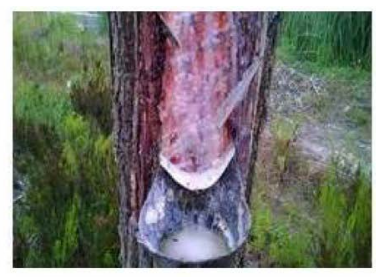

(b)

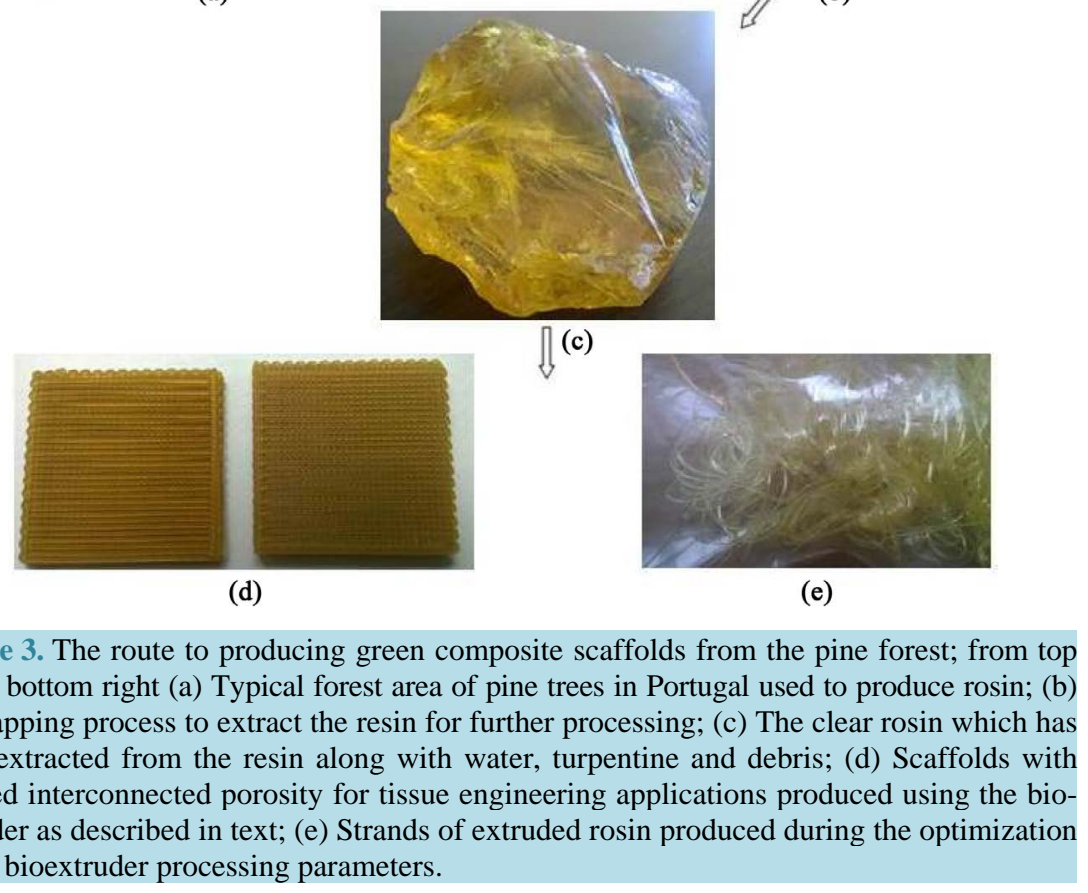

In this research project we explore the use of rosins as a precursor for advanced biomedical applications. We believe this would be a gateway for many pine associated industry. Moreover, create job opportunities for the people who rely on pine-based materials such as those who own land of pines with little or no productivity, for growing trees, collection of resins (tapping the trees), storage and supplying for generation of turpentine and rosins.

\section{Experimental}

\subsection{Materials and the General Procedure for the Preparation of Rosin Composite Scaffolds}

Gum rosins were obtained via local producers, Costa e Irmãos, Leiria, Portugal. Nanoclay was purchased from Aldrich and used as received. Experiments were conducted using standard laboratory glassware. The temperature of the reaction was controlled using a thermostatic laboratory hot plate.

\subsection{The Dual-Bioextruder}

Rosin composite scaffolds were produced using a bioextrusion system (Figure 4), which was developed by the Centre for Rapid and Sustainable Product Development (CDRSP) of the Polytechnic Institute of Leiria (IPL, Portugal). This system enables the fabrication of mono and multi-material scaffolds through a layer-by-layer manufacturing process [15].

The Dual-Bioextruder system results from a scientific collaboration project established between the CDRSP and the Institute of Health and Biomedical Innovation from Queensland University of Technology (Australia). It aimed at sharing scientific and technological knowledge regarding the field of Tissue Engineering and developing intelligent biological substitutes capable of replicating the structural and functional complexity of native tis- 


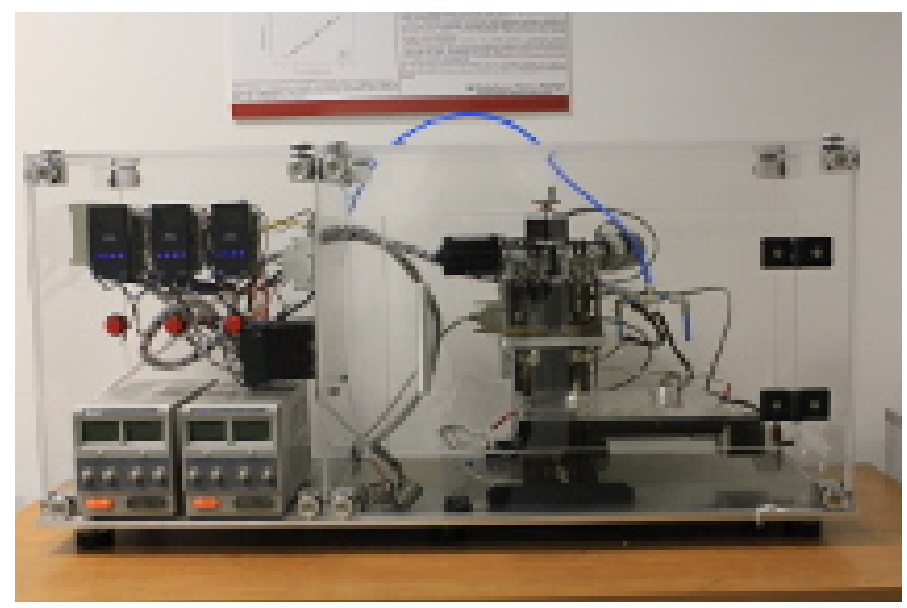

Figure 4. The Dual-Bioextruder system.

sues, namely bone and cartilage. This was a multidisciplinary project intending to place CDRSP in the front line of the Biofabrication domain through the development of unique competences in the areas of biomaterials, additive manufacturing technologies, in vitro and in vivo cell culture methodologies.

Rosin scaffolds were produced by deposition of fibers through a nozzle with a diameter of $400 \mu \mathrm{m}$. Scaffolds with dimensions of $15 \times 15 \times 2 \mathrm{~mm}$ and pore configuration of $0^{\circ} / 90^{\circ}$, were processed at $115^{\circ} \mathrm{C}$, using deposition velocity of $300 \mathrm{~mm} / \mathrm{min}$ and the screw rotation velocity of $40 \mathrm{rpm}$. Subsequent to these tests we found them to be the optimum parameters to produce the green composite scaffolds.

\subsection{Analytical Procedures}

\subsubsection{Thermogravimetric Analysis}

Thermogravimetric analysis (TGA) assays were performed using a STA 6000 (Perkin Elmer ${ }^{\circledR}$ ) equipped with Pyris software. Samples of $7 \mathrm{mg}$ were heated from $20^{\circ} \mathrm{C}$ to $600^{\circ} \mathrm{C}$. The heating rate was $10^{\circ} \mathrm{C} / \mathrm{min}$ under a constant purging of nitrogen $(20 \mathrm{ml} / \mathrm{min})$ and using an empty alumina pan as the reference.

\subsubsection{Scanning Electron Microscopy}

The scaffolds produced were coated with gold and examined in a high vacuum SEM (Cambridge Stereoscan S360 operating at $20 \mathrm{kV}$ using the secondary electron detector. The distribution of the nanoclay in the polymer matrix was examined using an Oxford instruments INCA system attached to the microscope which enabled maps of the elemental composition across the sample to be determined.

\section{Results and Discussion}

\subsection{Scaffolds Production}

Rosin composite scaffolds were successfully obtained in a 100\% green methodology using our own bioextrusion system as mentioned before. In the process we have explored a way that allows the processing of rosin however the extruded filaments (Figure 3) have a rather brittle nature for use as scaffolds for tissue engineering. Rosin with its structurally hydrophobic characteristics is usually difficult to disperse in natural clay or ionic salts in a polar or non-polar protic solvent medium. However, in bio-extrusion this issue was overcome as there was no solvent use and of course with moderate temperatures. We have managed to obtain rosin composite scaffolds via bioextruding rosins with the addition of nanoclay $30 \%(\mathrm{w} / \mathrm{w})$ at $115^{\circ} \mathrm{C}$. It is also noteworthy mentioning that nanoclay which consists of montomorillionite (MMT) has metal ions which can assist the scaffolds to be heavier and stronger thus improving properties.

\subsection{Thermogravimetric Analysis}

The thermal stability of the rosin and rosin with nanoclay $30 \%(\mathrm{w} / \mathrm{w})$ was investigated by thermogravimetric 
analyses. As shown in Figure 5, there are two weight loss stages for both samples. The first weight loss occurs below $120^{\circ} \mathrm{C}$ and is related to the evaporation of the absorbed water. The second step from TGA curve of the pure rosin, with an onset temperature of degradation $\sim 270^{\circ} \mathrm{C}$ and $98 \%$ of the total weight loss, is attributed to the degradation of the structure. These results were similar to the ones obtained by Donato et al. 2010 [16] and Tsanaktsidis et al. 2013 [17]. With the addition of nanoclay a decrease occurs at the onset temperature of degradation to $250^{\circ} \mathrm{C}, 66^{\circ} \mathrm{C}$ and at $600^{\circ} \mathrm{C}$ the composite has residual weights similar to nanoclay concentration.

\subsection{Scaffold Morphology}

Figure 6 shows the secondary electron images for strands of the rosin only compared with the equivalent strand based on rosin with nanoclay $30 \%(\mathrm{w} / \mathrm{w})$. The rosin strands are smooth and regular with a width of $\sim 400 \mu \mathrm{m}$. The nanocomposite based strands of the composite show a small regular variation of $\sim 5 \%$ in thickness of the strands. Other than that slight variation, the scaffold is well defined with strand spacing which defines the porosity.

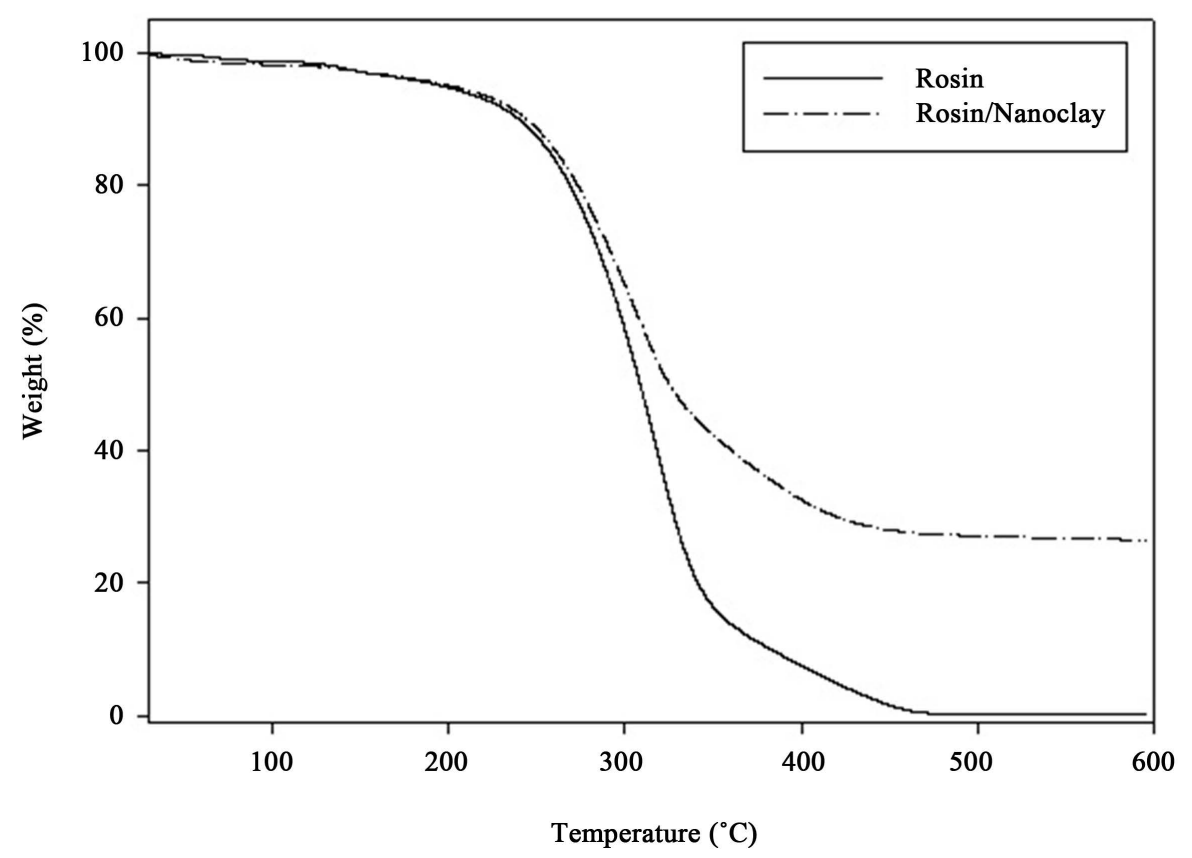

Figure 5. Thermogravimetric analysis of Rosin and Rosin/Nanoclay.

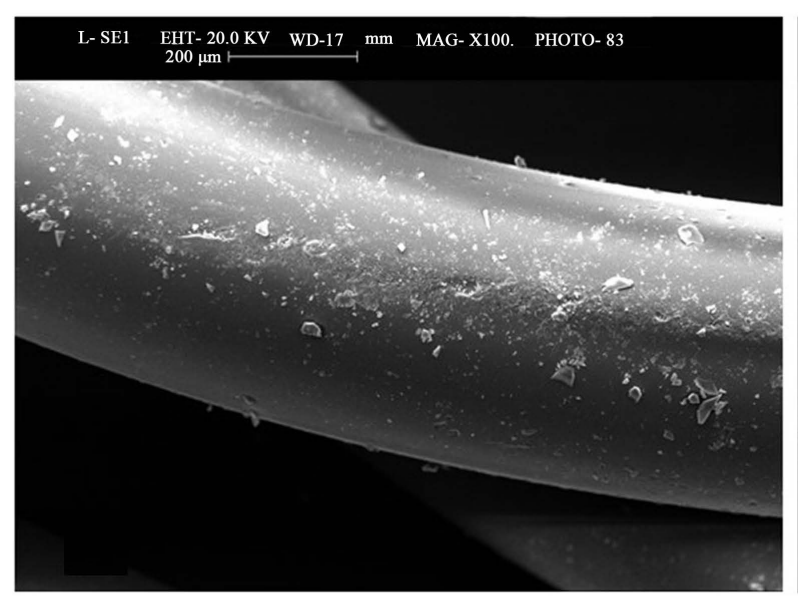

(a)

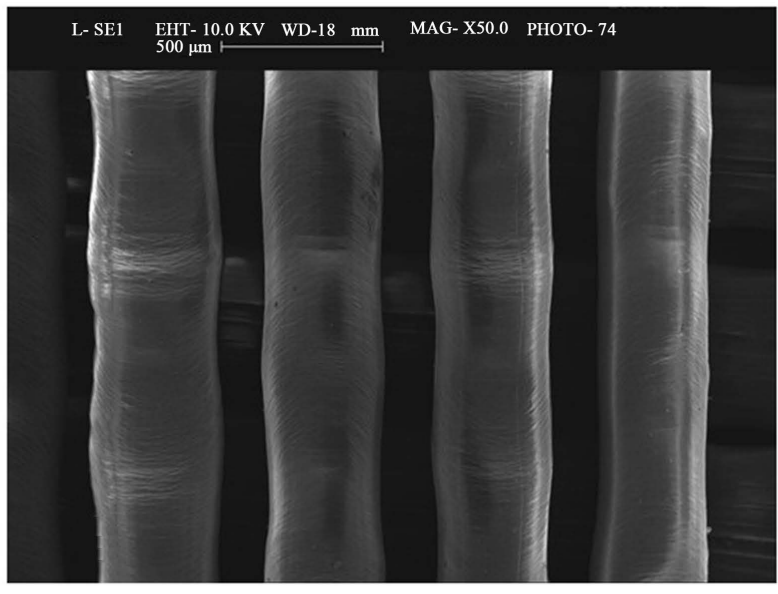

(b)

Figure 6. Scanning electron microscopic images of (a) Rosin filaments and (b) Rosin/30\% Nanoclay scaffold. 


\section{Conclusions}

The fusion of rosin with nanoclay permitted the production of green composite scaffolds using a bioextrusion system for number of samples. Scaffolds were successfully produced presenting aligned filaments, good geometry and porosity. TGA results demonstrated that the degradation temperatures of the samples are above the processing temperatures used to produce the rosin scaffolds, which ensure no decomposition of the materials used during the extrusion process.

We anticipate that other products can be produced using different melt processing equipment with nanoclay as a filler/viscosity modifier.

Finally we believe as the green composite scaffolds are made of using bio-degradable materials in the process and of the low energy consumption have the potential for advance green science.

\section{References}

[1] NACE Rev. 2, Divisions 16, 31, 17, 18.1. Relevant Wood Harvesting Aspects (NACE Rev. 2, Group 2.2) Are Also Covered in This Blueprint. http://eurlex.europa.eu/LexUriServ/LexUriServ.do?uri=OJ:L:2006:393:0001:0039:EN:PDF

[2] Commission Communications: A Stronger European Industry for Growth and Economic Recovery: Industrial Policy Communication Update (COM(2012)582 of 10.10.2012) and Integrated Industrial Policy for the Globalisation Era: Putting Competitiveness and Sustainability at Centre Stage (COM(2010)614 of 28.10.2010).

[3] Oy, I. (2013) Wood Raw Material Supply and Demand for the EU Wood-Processing Industries. Study for DG Enterprise and Industry.

[4] Madhavan Nampoothiri, K., Nair, N.R. and John, R.P. (2010) An Overview of the Recent Developments in Polylactide (PLA) Research. Bioresource Technology, 101, 8493-8501. http://dx.doi.org/10.1016/j.biortech.2010.05.092

[5] Lu, Y., Wei, X., Zong, Z., Zhao, W. and Cao, J. (2013) Structural Investigation and Application of Lignins. Progress in Chemistry, 25, 838-858.

[6] Peng, F., Peng, P., Xu, F. and Sun, R.C. (2012) Fractional Purification and Bioconversion of Hemicelluloses. Biotechnology Advances, 30, 879-903. http://dx.doi.org/10.1016/j.biotechadv.2012.01.018

[7] Wilbon, P.A., Chu, F. and Tang, C. (2013) Progress in Renewable Polymers from Natural Terpenes, Terpenoids, and Rosin. Macromolecular Rapid Communications, 34, 8-37. http://dx.doi.org/10.1002/marc.201200513

[8] Yao, K. and Tang, C. (2013) Controlled Polymerization of Next-Generation Renewable Monomers and Beyond. Macromolecules, 46, 1689-1712. http://dx.doi.org/10.1021/ma3019574

[9] Zhang, J. (2012) Rosin-Based Chemicals and Polymers. Smithers Rapra.

[10] http://www.goisproperty.co.uk/Gois_Portugal/Pine_Resin_production.html

[11] Langenheim, J.H. (2003) Plant Resins Chemistry Evolution Ecology and Ethnobotany. Timbers Press.

[12] Fiebach, K. and Grimm, D. (2000) Resins, Natural. Ullmann's Encyclopedia of Industrial Chemistry.

[13] Maiti, S., Ray, S.S. and Kundu, A.K. (1989) Rosin: A Renewable Resource for Polymers and Polymer Chemicals. Progress in Polymer Science, 14, 297-338. http://dx.doi.org/10.1016/0079-6700(89)90005-1

[14] Maiti, S., Das, S., Maiti, M. and Ray, A. (1983) Renewable Resources from Forest Products for High Temperature Resistant Polymers. In: Carraher, C.E. and Sperling, L.H., Eds., Polymer Publications of Renewable-Resource Materials, Plenum Press, USA, 129. http://dx.doi.org/10.1007/978-1-4613-3503-0_10

[15] Biscaia, S.I., Viana, T.F., Almeida, H.A. and Bártolo, P.J. (2015) Production and Characterisation of PCL/ES Scaffolds for Bone Tissue Engineering. Materials Today: Proceedings, 2, 208-216. http://dx.doi.org/10.1016/j.matpr.2015.04.024

[16] Donato, D.I., Lazzara, G. and Milioto, S. (2010) Thermogravimetric Analysis-A Tool to Evaluate the Ability of Mixtures in Consolidating Waterlogged Archaeological Woods. Journal of Thermal Analysis and Calorimetry, 101, 10851091. http://dx.doi.org/10.1007/s10973-010-0717-9

[17] Tsanaktsidis, C.G., Favvas, E.P., Scaltsoyiannes, A.A., Christidis, S.G., Katsidi, E.X. and Scaltsoyiannes, A.V. (2013) Natural Resins and Their Application in Antifouling Fuel Technology Part I: Improving the Physicochemical Properties of Diesel Fuel Using Natural Resin Polymer as a Removable Additive. Fuel Processing Technology, 114, 135-143. 